\title{
O cenário educacional: $O$ professor e a Tecnologia da Informação e Comunicação diante das mudanças atuais
}

\author{
Mainardi Andreia', Liziany Muller², Aline Pereira de Arruda Rech ${ }^{3}$ \\ 'Universidade Federal de Santa Maria, Santa Maria,RS, Brasil
}

\section{Resumo}

O objetivo deste trabalho é avaliar a inserção das Tecnologias da Informação e Comunicação (TIC) como ferramentas de apoio pedagógico na Escola Municipal de Ensino Fundamental Otaviano Paixão Coelho, de Lagoão-RS. A metodologia foi da pesquisa exploratória qualitativa, sendo os dados avaliados a partir da aplicação de questionários tipo survey, para os professores da escola. Ressalta-se que antes da aplicação do questionário foi assistido o vídeo "Educação em Rede" (http://www.youtube.com/watch?v=AJ1P6aeR6Lo). Os resultados obtidos apontam para o desafio de educar para a inovação e a mudança, planejando e implantando propostas dinâmicas no ensino tanto no que tange a capacitação adequada dos professores quanto ao planejamento e a metodologia que promovam a motivação dos estudantes e dinamização do processo ensino-aprendizagem vinculados às concepções sócio-históricas da educação, nos aspectos cognitivo, ético, político, cientifico, cultural, lúdico e estético. Evidencia-se a necessidade da mudança no papel do professor, qualificando-o para buscar maneiras de agir pedagogicamente com as TIC, para que professores e alunos conheçam, interpretem, utilizem, reflitam criticamente a tecnologia para não serem dominados, promovendo o desenvolvimento integral do homem, a inovação, a renovação da educação, tornando crítico e reflexivo o ensino, permitindo assim, a melhoria qualitativa do processo educativo.

Palavras-chave: TIC- Ensino Fundamental- educadores- aprendizagem.

\begin{abstract}
The objective of this study it evaluates the integration of Information and Communication Technologies (ICTs) as tools to support teaching in the School Hall Elementary School Octavian Passion Rabbit. The exploratory research methodology was qualitative and he data evaluated from the survey type questionnaire for teachers soft the school. It is noteworthy that before the questionnaire was watching the video Education Network (http://www.youtube.com/watch?v=AJIP6aeR6Lo). The results point to the challenge of educating for innovation and change, planning and deploying dynamic teaching both proposals regarding the adequate training of teachers in planning and methodology to promote student motivation and promotion of the teaching-learning linked the socio-historical conceptions of education, in the cognitive, ethical, political, scientific, cultural, recreational and aesthetic. This study highlights the need for change in the role of teacher, qualifying them to seek ways to act pedagogically with ICT for teachers and students to know, interpret, use, reflect critically technology to not be dominated by promoting the integral development of man, innovation, renewal of education, making critical and reflective teaching, thus allowing the qualitative improvement of the educational process.
\end{abstract}

Keywords: ICT - Elementary school- educator- sand learning. 


\section{INTRODUÇÃO}

Atualmente, as tecnologias passaram a ser ferramentas essenciais na educação e precisam estar presentes em sala de aula, auxiliando na mediação da informação e no processo de ensino-aprendizagem.

A evolução social do homem confunde-se com as tecnologias desenvolvidas e seus avanços em cada época em diferentes períodos da história da humanidade (KENSKI, 2010). O autor também relata que "a evolução tecnológica não se restringe apenas aos novos usos de determinados equipamentos e produtos, ele altera comportamentos, transforma a maneira de pensar, sentir e agir, mas não apenas o comportamento individual, mas o de todo grupo social."

Há tempos um acelerado desenvolvimento exige que uma nova maneira de ensinar e aprender seja incluída no cotidiano escolar e, que os professores reflitam que livros, cadernos e quadro negro deixaram de ser a única maneira de trabalhar, pois o computador, a internet e uma série de tecnologias são recursos fundamentais para uma educação renovada e dinâmica.

$\mathrm{O}$ avanço da tecnologia permitiu que o acesso à informação se tornasse muito mais rápido e fácil, e, como não poderia ser diferente, o meio acadêmico também foi atingido. O giz, o quadro negro, o caderno e os livros já não são mais as únicas ferramentas utilizadas em sala de aula. (ALMEIDA; PRADO 2009). Os autores ainda afirmam que o uso de tecnologias como apoio ao ensino e à aprendizagem vêm evoluindo vertiginosamente nos últimos anos, podendo trazer efetivas contribuições à educação, presencial ou à distância.

As tecnologias da Informação e Comunicação (TIC) oferecem tanto ao professor quanto ao aluno infinitas possibilidades de adquirir e compartilhar informações e, por isso é preciso que uma evolução significativa aconteça nas escolas e nas metodologias usadas pelos professores. A globalização exige instituições educacionais preparadas para aderir às tecnologias, de forma que a inclusão digital comece pelo professor, sendo necessário o conhecimento dos recursos oferecidos pelas mídias educacionais.

A incorporação das TIC na escola e na prática pedagógica não pode se restringir a formação dos professores, mas deve voltar-se também para a percepção de dirigentes escolares, propiciando-lhes um domínio dos recursos dessa tecnologia que possa auxiliar na gestão escolar, e simultaneamente, provocar a tomada de consciência sobre as contribuições dessa tecnologia ao ensino e a aprendizagem (ALMEIDA, 2003, p.118).

A rápida expansão das TIC nas variadas áreas está trazendo desafios à escola e, o professor como mediador do conhecimento necessita integrar-se, utilizando as mesmas como recurso no aprimoramento da aprendizagem. Conforme

Lévy (1999, p. 171) é:

A partir daí, a principal função do professor não pode mais ser uma difusão de conhecimentos, que agora é feita de forma mais eficaz por outros meios. Sua competência deve deslocar-se no sentido de incentivar a aprendizagem e o pensamento. O professor deve tornar-se um animador da inteligência coletiva dos grupos que estão a seu encargo. Sua atividade será centrada no acompanhamento e na gestão das aprendizagens: o incitamento à troca dos saberes, a mediação relacional e simbólica, a pilotagem personalizada dos percursos de aprendizagem etc.

A autora nos mostra que diante do avanço tecnológico, as formas de compartilhar o conhecimento e a informação precisam evoluir, fazendo com que as aulas sejam um processo educacional atrativo e renovado. Por isso, faz-se necessário avaliar a inserção das Tecnologias da Informação e Comunicação (TIC) como ferramentas de apoio pedagógico na Escola Municipal de Ensino Fundamental Otaviano Paixão Coelho de Ronda Alta -Lagoão- RS, a qual será feita a pesquisa, para assim compreender os anseios e dificuldades que os docentes encontram quanto ao uso das TIC, e uma reflexão sobre suas aulas aconteça, instigando os mesmos a reconhecerem a importância do uso das tecnologias em suas aulas nos dias de hoje. 


\section{METODOLOGIA}

O trabalho foi desenvolvido na Escola Municipal de Ensino Fundamental Otaviano Paixão Coelho, localidade de Ronda Alta, zona rural do município de Lagoão, sendo a mesma fundada em 1963.

A comunidade de Ronda Alta pertencia ao município de Soledade - RS, sendo que após a emancipação de Lagoão em 1988, passou a fazer parte desse. Dizem que Ronda Alta é a comunidade que tem a maior quantidade de negros do município. É um lugar onde circulam homens e mulheres em alianças matrimoniais com muitos filhos e possuem 121 famílias, cada uma com 5 pessoas em média. A principal atividade econômica é a agricultura, tendo como principal o plantio do fumo. No geral é uma comunidade de classe média-baixa.

A escola atende várias comunidades vizinhas, por isso leva nome de Escola Polo do município. Atualmente possui a Educação Infantil (Pré-Escolar A e B) e Ensino Fundamental ( $1^{\circ}$ ano ao $9^{\circ}$ ). A escola tem objetivo de desenvolver habilidades e competências na perspectiva de uma educação comprometida com o desenvolvimento integral do educando, transformar a escola em um espaço de integração, valorizar a própria vida, a vida do próximo e o meio ambiente, enfatizando a importância do respeito, diálogo, humildade e amor.

A escola possui nove (9) salas de aula, uma (1) sala de professores, uma (1) secretaria onde funciona o Laboratório de Informática com acesso à internet, uma (1) biblioteca com reduzido espaço e, um (1) ginásio de esportes. A escola possui 14 computadores, um data show, que é pouco utilizado, uma máquina de Xerox e duas impressoras multifuncionais.

O corpo docente é constituído por 25 professores. A designação dos docentes é feita pela entidade mantenedora responsável (Prefeitura Municipal). Também, a maioria dos professores desta escola afirma não ter competência e habilidades para trabalharem com as TIC na sala de aula, uma vez que não tiveram em seus currículos.

O corpo discente é constituído por cerca de 310 alunos. O aluno individualmente ou em grupo, conta em especial, com a atenção do professor conselheiro de turma. Na ocasião da matrícula, o aluno assume o compromisso de observar as disposições regimentais da escola.

Quanto ao tipo de pesquisa, ela pode ser compreendida como um estudo dentro da modalidade de uma pesquisa-ação, num paradigma construtivista de uma pesquisa qualitativa com professores, onde foi utilizado como instrumento para o mesmo um questionário (anexo) com questões abertas e fechadas relativas a equipamentos disponíveis na escola e utilização dos mesmos, caracterização

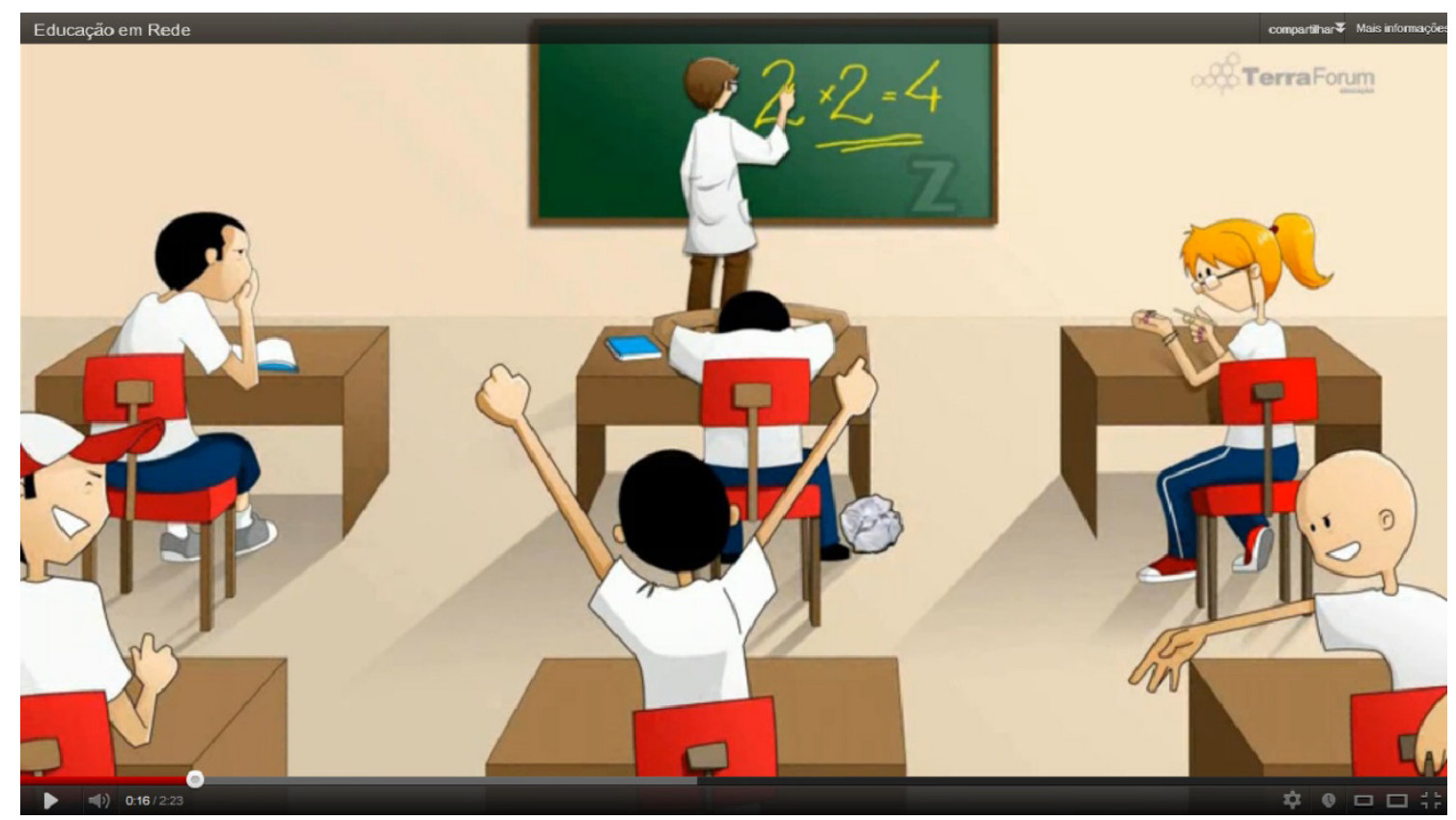

Figura 1- Imagem ilustrativa do vídeo assistido pelos professores.

Fonte http://www.youtube.com/watch?v=AJ1P6aeR6Lo 
dos professores quanto ao uso ou não das TIC em suas aulas, dificuldades encontradas e, preparo dos professores para utilizá-las como práticas pedagógicas no auxilio de suas aulas.

A coleta de dados foi no final mês de setembro, em uma reunião pedagógica, onde antes da aplicação do questionário foi assistido o vídeo "Educação em Rede" (http://www.youtube.com/ watch?v=AJ1P6aeR6Lo), como maneira de problematização e reflexão sobre o uso das TIC, como ferramenta no auxilio do professor em suas aulas. Foram investigados 25 professores, envolvendo $100 \%$ da população em questão e, após foram analisadas as respostas e considerações dos aspectos pesquisados para assim realização das considerações finais.

\section{ANÁLISE DOS RESULTADOS}

Conhecer o perfil dos professores de escolas municipais quanto ao uso das Tecnologias da Informação e Comunicação é fundamental, para o aprimoramento do processo de ensino-aprendizagem no ambiente escolar.

A maioria dos professores, $92 \%$, são do sexo feminino (Gráfico 1) e de acordo com o gráfico 2 , que representa a idade dos entrevistados, verificou-se que a mesma é bem diversificada nessa escola, tendo professores de várias faixas etária, sendo a maioria deles de 31 a 35 anos, o que corresponde a 35\%.

Gráfico 1: Percentual do Sexo dos Professores.

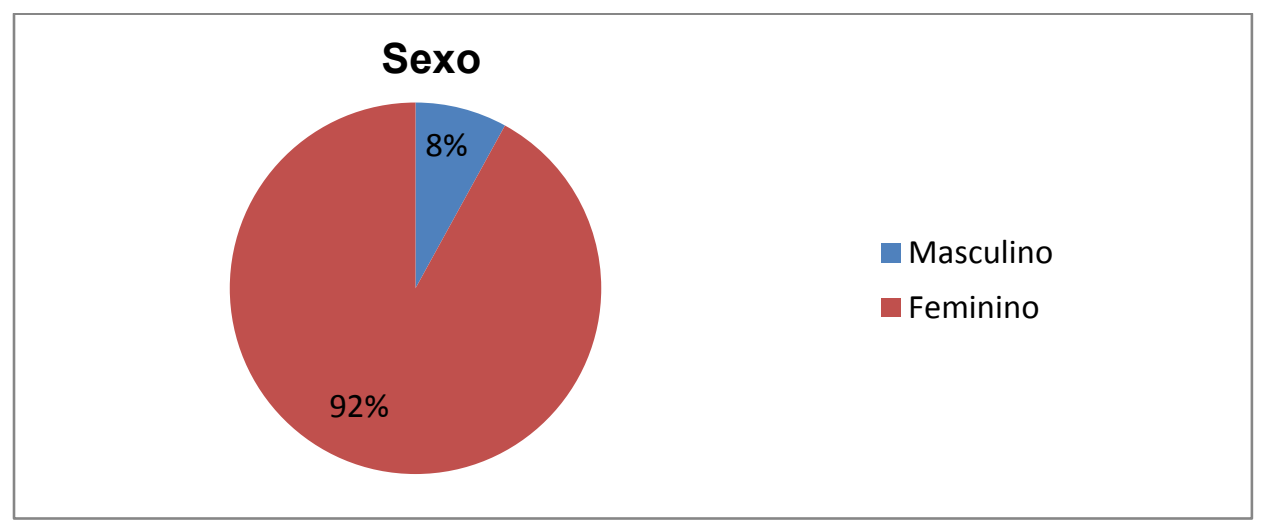

Gráfico 2: Idade dos Professores.

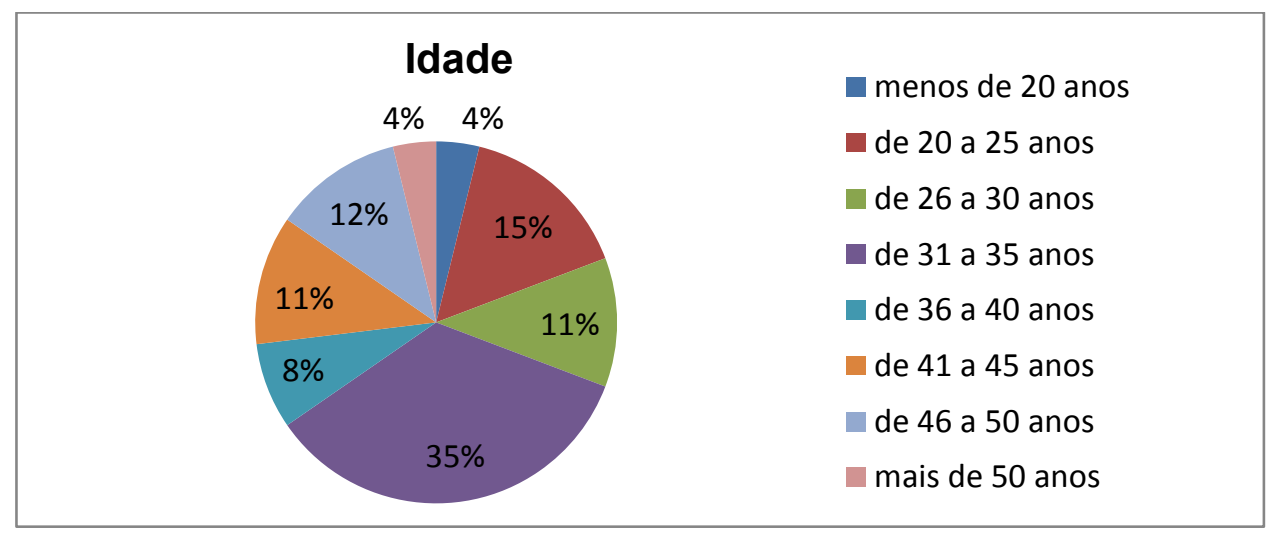

Em relação à formação dos professores desta escola, percebe-se que mesmo nos dias de hoje, onde muitas oportunidades de aperfeiçoamento são encontradas, com facilidades e flexibilidade para estudar, como a educação à distância, por exemplo, ainda há professores somente com o magistério (Gráfico 3).

Assim, pode-se ver a necessidade de uma atenção especial aos docentes que ainda não alcan- 
çaram o nível superior de ensino. Porém, como o aluno, o professor também é esse sujeito atuante na sociedade e em todas as épocas precisa se adaptar, se moldar aos novos métodos de ensino, às novas formas de ensinar e abordar os conteúdos. Nesse sentido Perrenoud (2000, p. 10) diz o seguinte: "[...] a evolução exige que todos os professores possuam competências antes reservadas aos inovadores ou aqueles que precisavam lidar com públicos difíceis".

Gráfico 3: Formação dos professores.

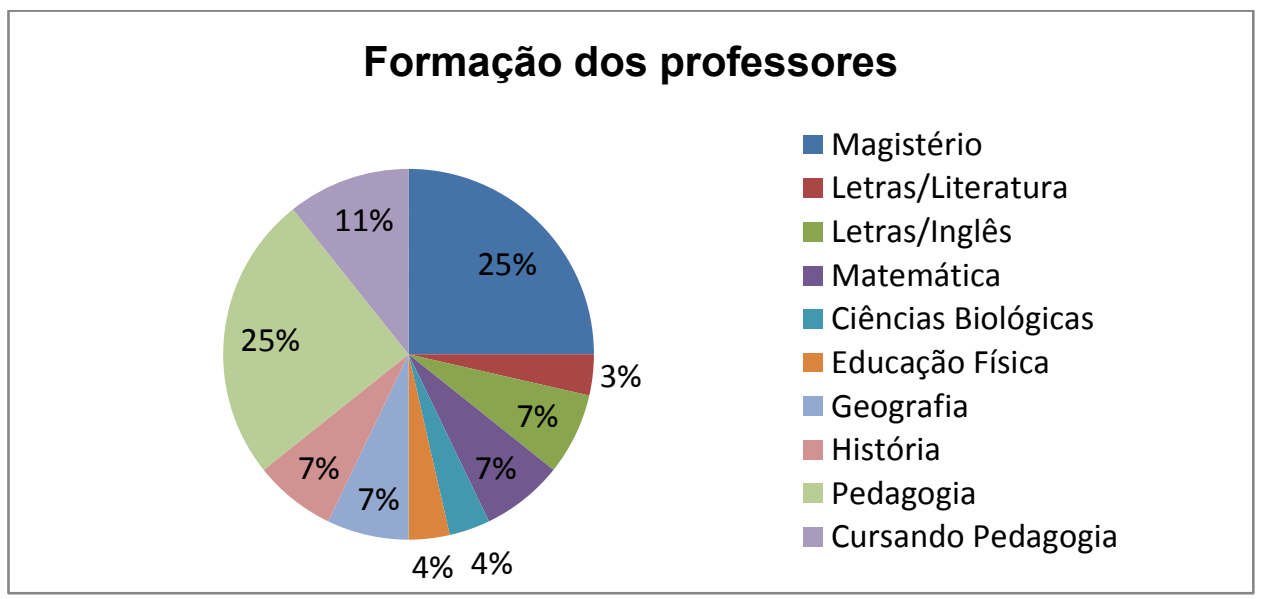

Quanto ao número de alunos que os professores possuem, representado no gráfico 4, o mesmo é bem variado. Pode-se observar que a maioria dos professores (52\%) trabalha com mais de 50 alunos, isso se deve aos docentes que trabalham em diferentes turmas, de $5^{\circ}$ ano a $8^{\mathrm{a}}$ série.

Gráfico 4: Número de alunos que os professores possuem.

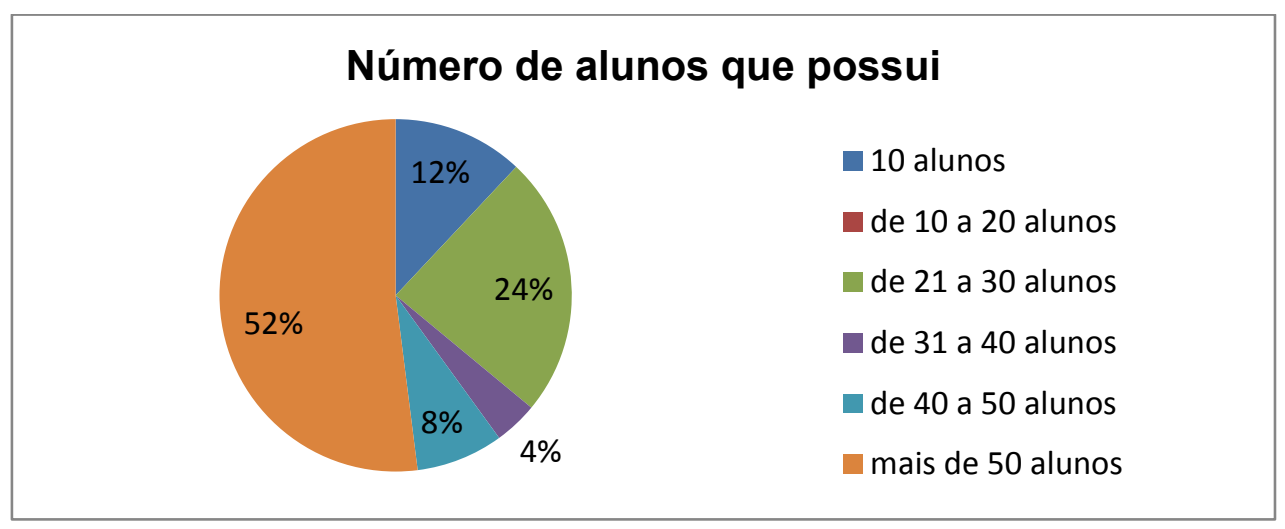

Observa-se través do gráfico 5 , que o jornal impresso ainda hoje é o mais utilizado por esses professores desta escola, (41\%), seguido da internet com $22 \%$.

Suportes midiáticos populares com penetração social: jornais, revistas, rádio, cinema, vídeo, etc, são baseados no uso da linguagem oral, da escrita e da síntese entre som, imagem e movimento, o processo de produção e o uso desses meios correspondem a tecnologias especificas de informação e comunicação as TIC. (KENSKI, 2010).

Entretanto, para que o professor possa evoluir pautado na sociedade da informação é necessária sua inclusão digital, bem como o entendimento da importância da utilização das tecnologias da informação e comunicação dentro do ambiente escolar. A necessidade do professor dominar os recursos pode ser entendido como exigência de alfabetização tecnológica deste profissional e não pode ser compreendida apenas como um uso mecânico dos recursos tecnológicos, mas deve abranger também o domínio crítico da linguagem tecnológica para que os docentes atuem no preparo de cidadãos capazes de lidar com o avanço tecnológico, participando dele e de suas consequências ( SAMPAIO; 


\section{LEITE, 1999).}

Tarja (2000, p.128), destaca que "a internet traz muitos benefícios para a educação tanto para professores como para alunos. Com ela é possível facilitar as pesquisas, sejam grupais ou individuais, e o intercâmbio entre professores e alunos, permitindo a troca de experiência entre eles".

Gráfico 5: Quais TIC os professores utilizam para manter-se informados.

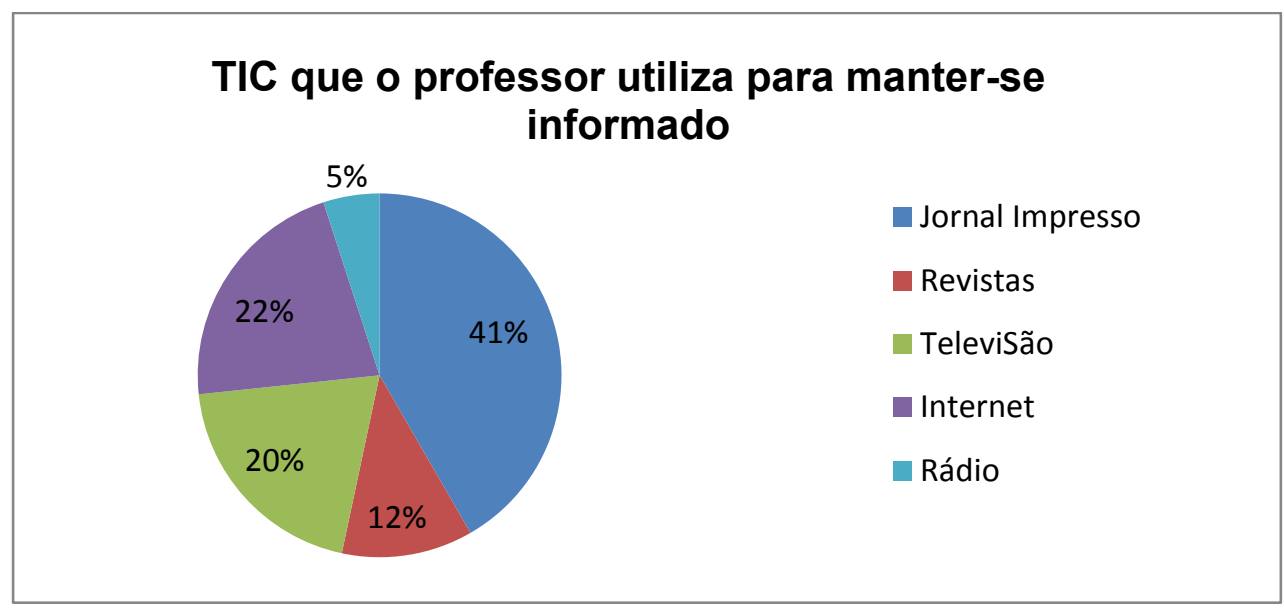

Ao observar os resultados do gráfico 6, percebe-se que $76 \%$ dos professores nunca realizaram capacitação para o uso das TIC.

A velocidade das alterações no universo informacional exige atualização permanente, pois as tecnologias estão em permanente mudança. A aprendizagem por toda a vida torna-se consequência natural do momento social e tecnológico em que vivemos, a sensação é de que quanto mais aprendemos mais se tem a estudar para se atualizar (KENSKI, 2010).

Gráfico 6: Professor já realizou algum curso de capacitação para uso das TIC.

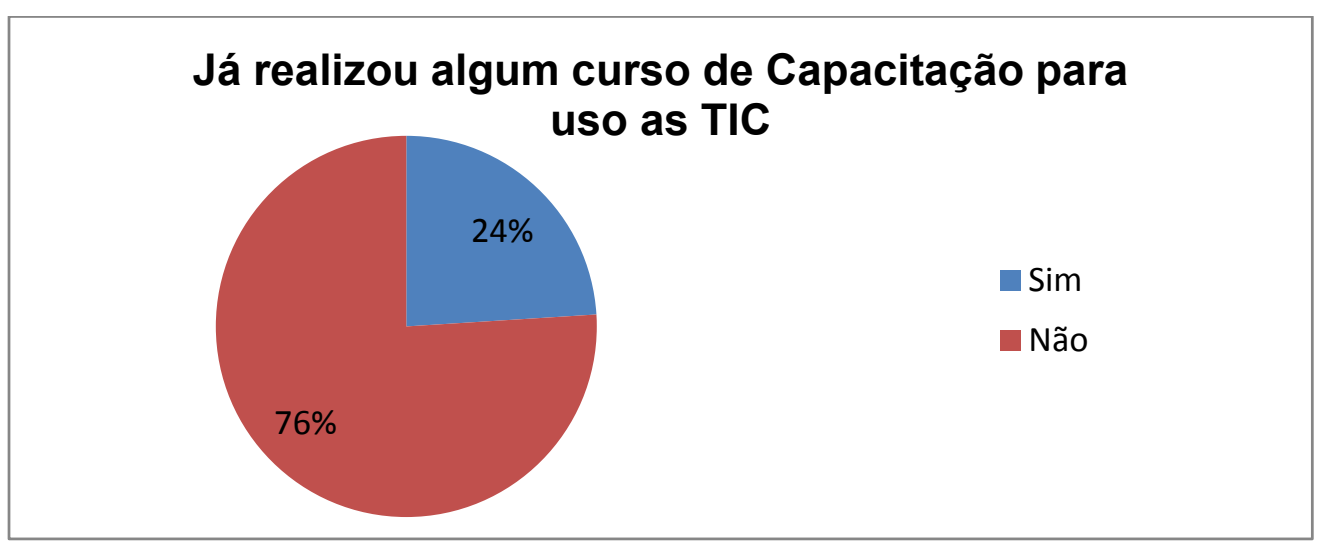

A maioria dos entrevistados afirmou que os recursos que a escola possui estão sempre à disposição para o uso (gráfico 7), o que é muito importante, pois assim a oportunidade de utilização aumenta, proporcionando ao professor que prepare suas aulas com variados recursos. Conforme KENSKI (2010), "a escola deve pautar-se pela intensificação das oportunidades de aprendizagem e autonomia dos estudantes em busca de conhecimentos, da definição de seus caminhos, da liberdade para que possam criar oportunidades e serem sujeitos da própria existência". 
Gráfico 7: Disponibilidade dos recursos Tecnológicos na escola

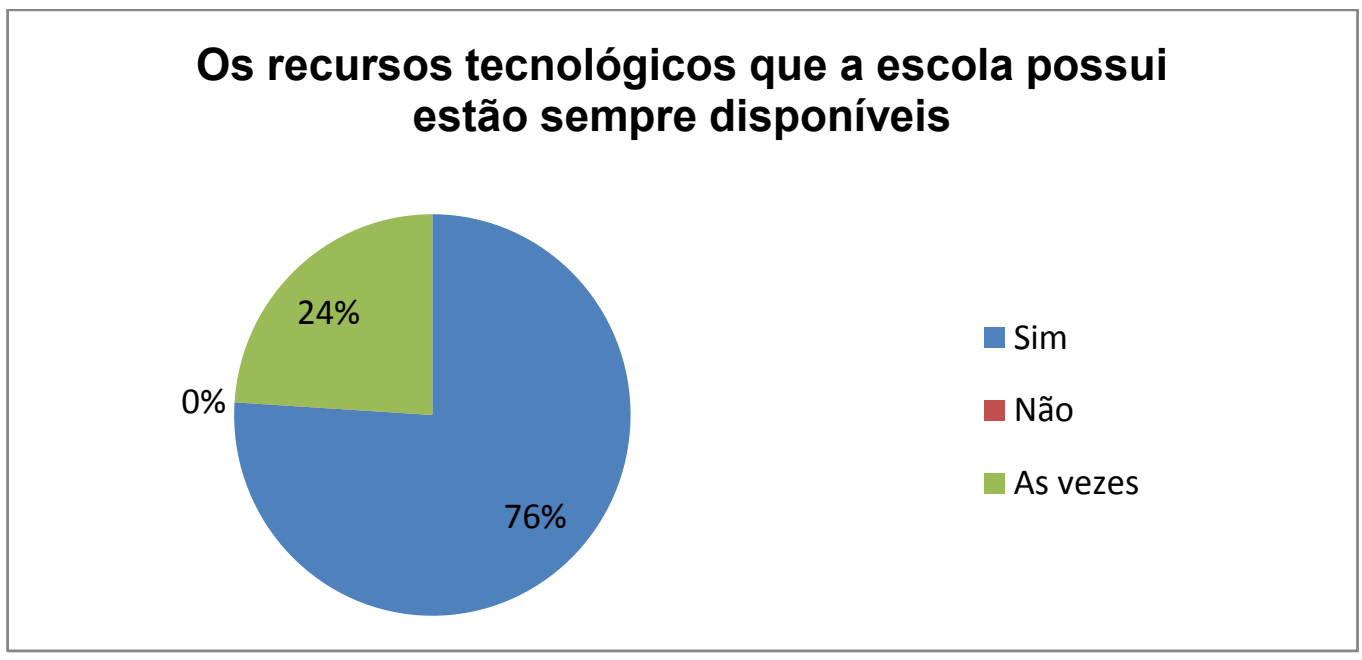

Constata-se através do gráfico 8, que mesmo a escola possuindo os recursos tecnológicos, estes ainda precisam ser mais utilizados pelos professores nas práticas pedagógicas, como auxílio no processo de ensino-aprendizagem dos alunos.

As TIC não são apenas meros suportes tecnológicos, elas têm suas próprias lógicas, linguagens e maneiras particulares de comunicar-se com as capacidades perceptivas, emocionais, cognitivas, intuitivas e comunicativas das pessoas, como por exemplo, a TV digital oferece condições de interação e manipulação personalizadas das informações (KENSKI, 2010). O autor ainda afirma que "as TIC evoluem com muita rapidez, a todo instante surgem novos processos e produtos diferenciados e sofisticados, telefones celulares, softwares, vídeos, computador multimídia, internet, televisão interativa, videogames, etc. Esses produtos, no entanto, não são acessíveis a todas as pessoas, pelos seus altos preços e necessidades de conhecimentos específicos para sua utilização".

Gráfico 8- Quais TIC os professores utilizam com mais frequência.

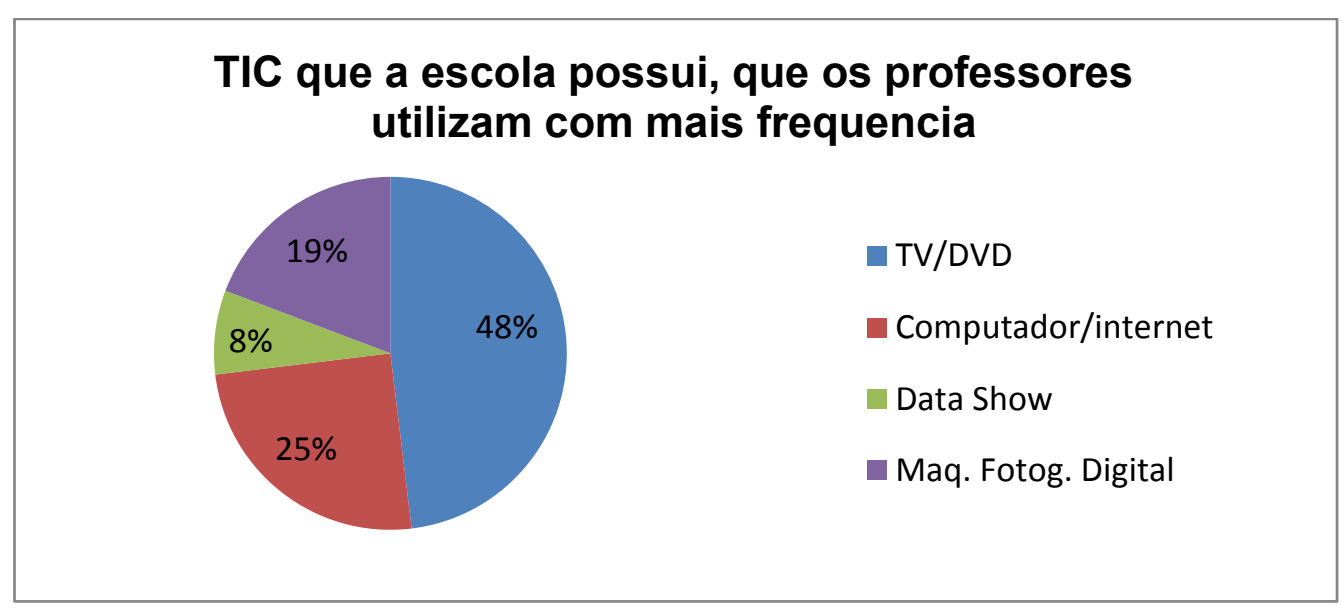

Questionou-se também quanto à experiência com computador e internet e, a maioria dos entrevistados (68\%) possui alguma experiência com computador e internet (gráfico 9), apesar de não terem tido nenhuma capacitação (Gráfico 6).

Evidencia-se que diante da necessidade de serem diversificadas as possibilidades e formas de agir e aprender, inserir-se as tecnologias da informação e comunicação abrem oportunidades para ação dos indivíduos e diversificação e transformação de ambientes de aprendizagem (MARTINSI, 2008). 
Gráfico 9: Experiência e domínio dos professores com computador e internet.

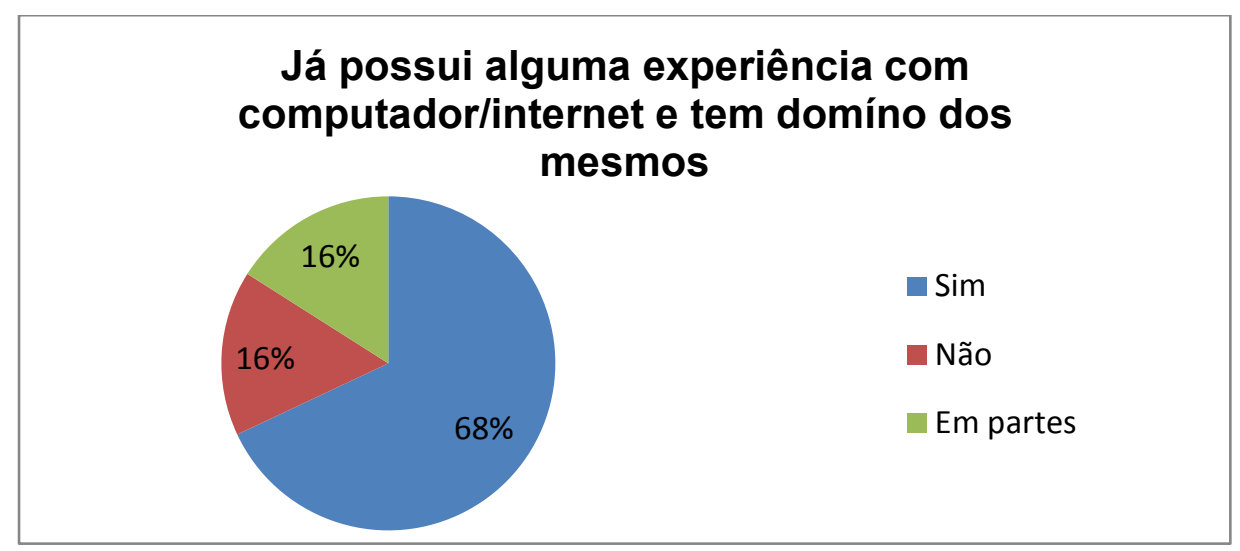
suas aulas.

Conforme gráfico 10, a maioria dos professores utiliza o computador/internet para preparar

$\mathrm{O}$ uso criativo das tecnologias pode auxiliar os professores a transformar o isolamento, a indiferença e alienação com o que costumeiramente os estudantes enfrentam em salas de aula, em interesse e colaboração, por meio dos quais eles aprendem a aprender, a respeitar, a aceitar a serem pessoas melhores e cidadãos participativos (KENSKI, 2010).

Gráfico 10: Utilização do computador/internet pelos professores na preparação suas aulas.

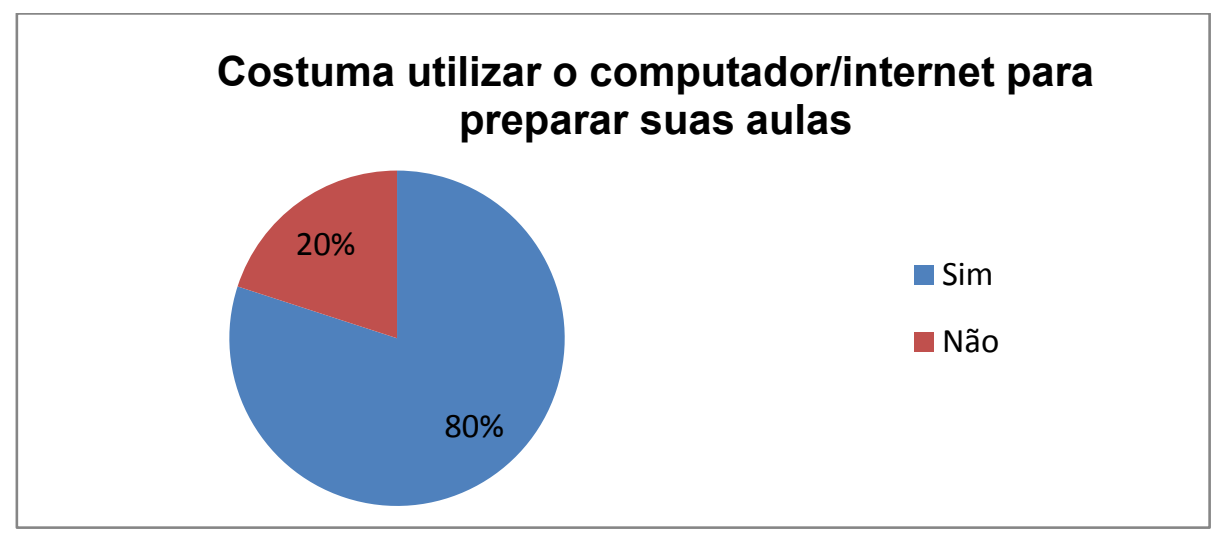

Gráfico 11: Quais ferramentas os professores utilizam para preparar suas aulas.

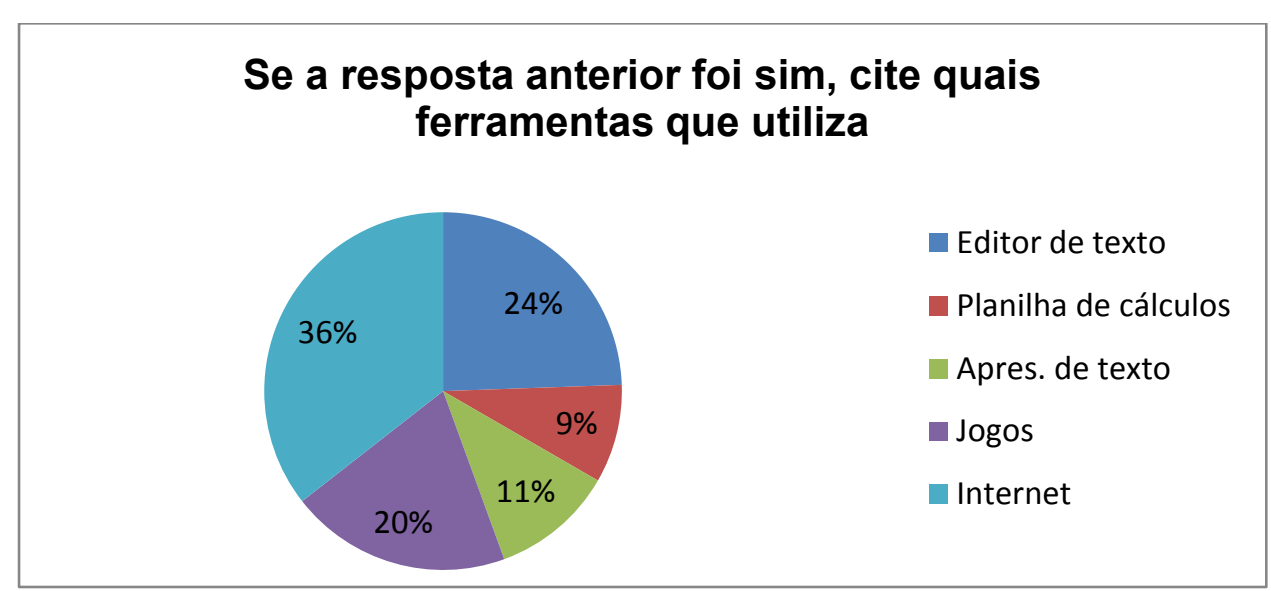


Para os docentes que responderam sim na questão 10, algumas alternativas de ferramentas que os mesmos utilizam poderiam ser citadas na questão 11 . Percebe-se no gráfico 11 que, o mais alto percentual de respostas foi a opção internet, com $36 \%$, sendo que as demais alternativas também foram marcadas. Os entrevistados poderiam marcar quantas ferramentas quisessem. Assim, PORTO (2009, pag.47), acrescenta que "uma forma de pesquisa muito utilizada ultimamente é a busca pela internet. Ela exige, no entanto, paciência e concentração, para não se perder pelos muitos endereços oferecidos, pelo resultado da busca. O ideal é que se procure em portais de busca que são mais conhecidos e, em um primeiro momento que sejam abertos endereços que contenham sites que abordem diretamente o assunto pesquisado".

Gráfico 12- Percentual de professores que utiliza o Laboratório de Informática da escola com os alunos

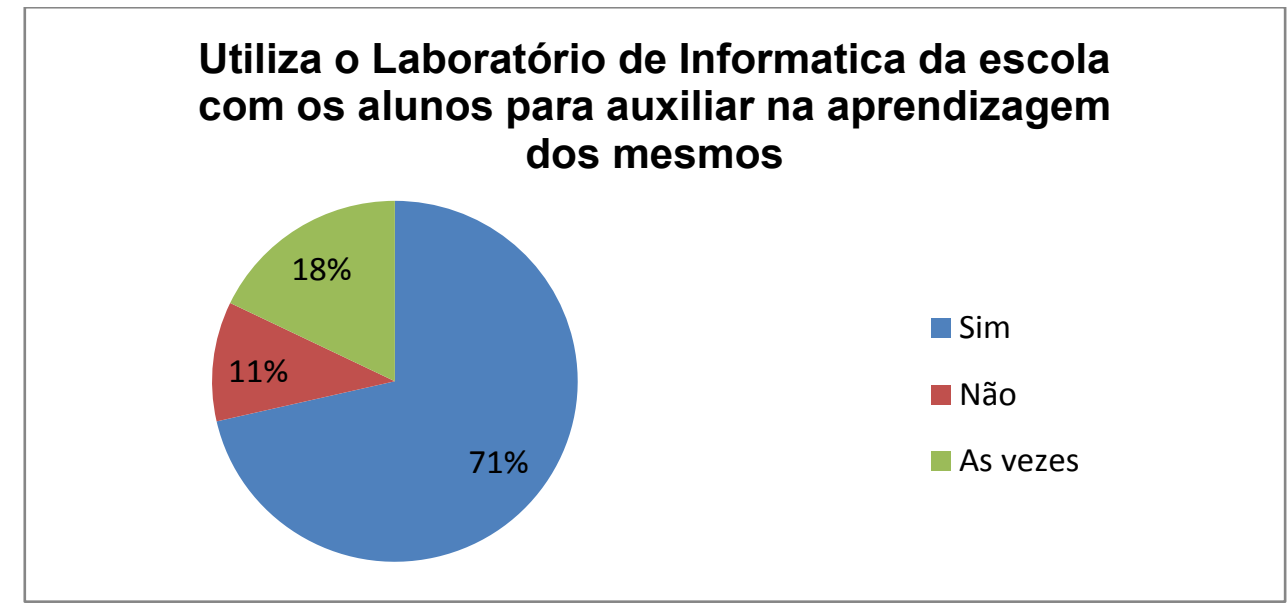

Constata-se através do gráfico 12 , a grande maioria dos professores (71\%), utiliza o laboratório de informática com seus alunos para auxiliar na aprendizagem dos mesmos, porém ainda temos aqueles que não utilizam esse recurso, o que pode ser efeito da falta de experiência dos mesmos, como se pode ver no resultado obtido da questão 9.

A prática docente de qualidade tem exigido do professor formação continuada e habilidades que estão para além da dimensão curricular, as quais incluem o uso das TIC como um conteúdo de aprendizagem. São habilidades capazes de auxiliar o docente a romper com modelos existentes em prol da adoção crítica de tecnologias inovadoras (ENRICONE, 2006)

Gráfico 13: Avaliação da utilização do Laboratório de Informática pelos professores.

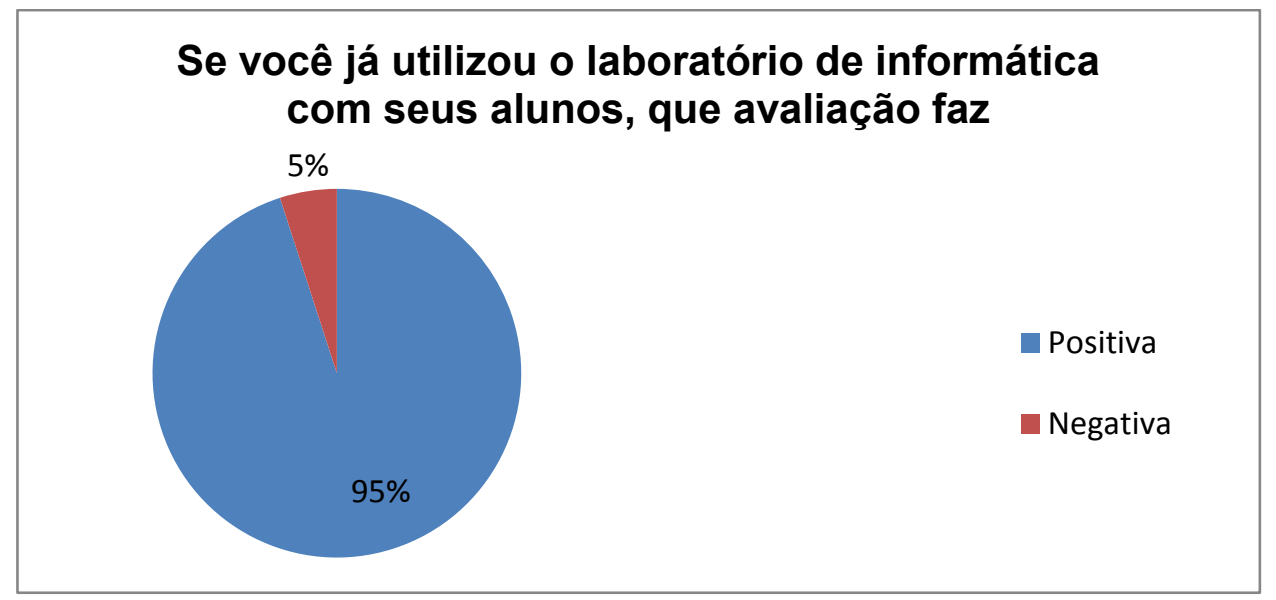


Para aqueles que responderam sim na questão 12 , questionou-se a avaliação que fizeram da utilização do laboratório de informática e, $95 \%$ dos entrevistados responderam que a avaliação foi positiva, como indica o gráfico 13. Hanze (2010) ressalta que "quando o professor desenvolve competências e habilidades para trabalhar com recursos tecnológicos, contextualizando suas atividades didáticas, esses procedimentos serão usados como mais uma ferramenta pedagógica enriquecedora do texto e do contexto que estão sendo trabalhados".

A maioria dos entrevistados afirmou que estimula seus alunos a usar o computador/internet, representado no gráfico 14, e quanto à sugestões de páginas para aqueles que afirmaram que sim, responderam que sugerem sites de acordo com as disciplinas e que estes tenham relação ao conteúdo desenvolvido. Assim, Moran (2009, p. 101), acrescenta que "os professores podem ajudar os alunos incentivando-os, a saber, perguntar, a enfocar questões importantes, a ter critérios na escolha de sites, de avaliações de páginas, a comparar textos com visões diferentes. Os professores podem focar mais a pesquisa do que dar respostas prontas. Podem propor temas interessantes e caminhar dos níveis mais simples de investigação para os mais coloridos e estimulantes para as mais abstratas, dos vídeos e narrativas impactantes para o contexto mais abrangente, com rupturas sucessivas e uma organização semântica contínua".

Gráfico 14: Professor, você estimula os alunos a usar o computador/internet, sugerindo páginas da web para pesquisas.

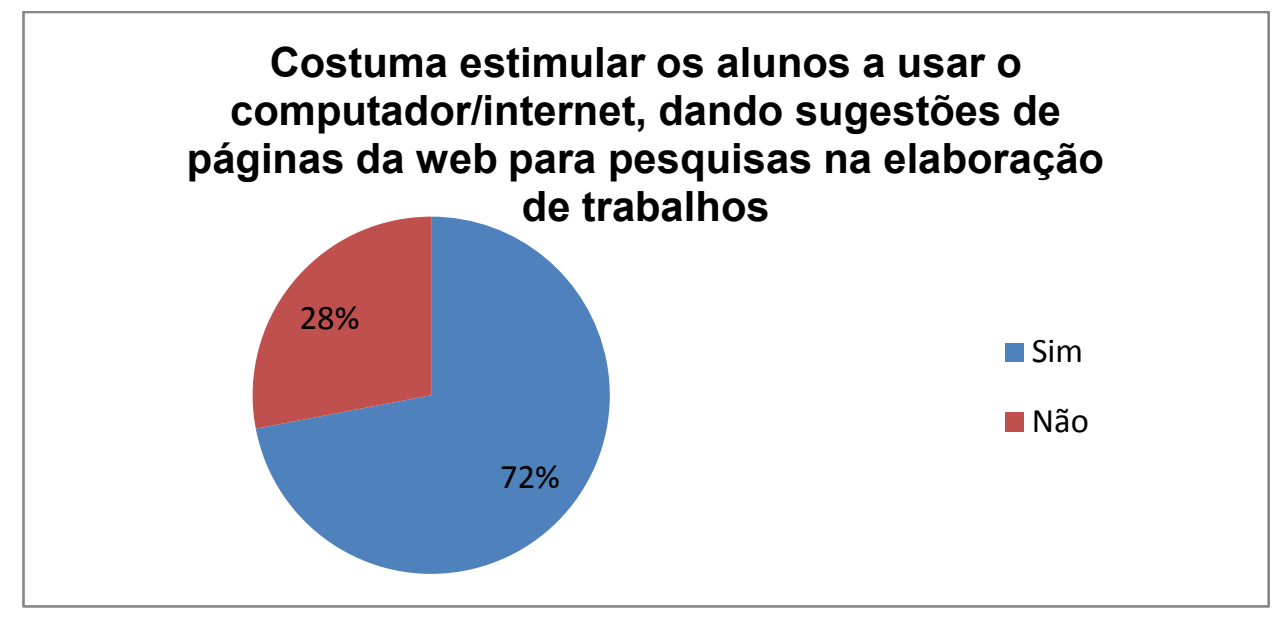

Quanto às dificuldades encontradas pelos entrevistados no que se referem ao uso das tecnologias em sala de aula, todos (100\%) afirmaram que encontram dificuldades, a maioria não sabe utilizá-las corretamente, principalmente o computador/internet e o data show, o que acaba limitando seu trabalho. Porém, o professor não pode ficar preso a dificuldade, precisa motivar-se e procurar o aperfeiçoamento, pois autores como Mercado (2002, p. 15) nos diz que "com as novas tecnologias, novas formas de aprender, novas competências são exigidas. Novas formas de realizar o trabalho pedagógico são necessárias e fundamentalmente, é neste ambiente telemático em que a tecnologia serve como mediador do processo de ensino aprendizagem".

Também foi perguntado se o entrevistado concorda que o uso das Tecnologias na Educação pode ajudar no ensino-aprendizagem e $100 \%$ afirmou positivamente.

Alunos que crescem em uma sociedade cercada de recursos tecnológicos possuem a capacidade de domínio rápido dos conteúdos abordados, bem como de interagir com mais eficácia e dinamismo com o próprio educador, exercício, questionários, leituras e outras atividades ficam mais atraentes quando são realizadas de forma inovadora e moderna. (DAMASCO, MERCADO, ABREU, 2007, pag.32).

$\mathrm{E}$ a respeito do vídeo assistido pelos entrevistados, foi perguntado se concordam que usando as tecnologias nas aulas e mudando o método de ensino, poderemos ver uma transformação significativa na aprendizagem dos alunos, todos afirmaram que sim, concordando que as mesmas devem ser introduzidas nas aulas.

Entretanto, para a inserção de tecnologias no processo de ensino aprendizagem exige muito 
mais do que simples adaptações das formas tradicionais de ensino aos novos equipamentos, sobretudo requer uma nova pedagogia que favoreça tanto o aprendizado personalizado quanto o cooperativo em rede, para que a potencialidade informativa e comunicativa das redes possa ser explorada é necessário que os professores estejam minimamente familiarizados com essas tecnologias e suas possibilidades pedagógicas, nesse sentido, é fundamental a redefinição do papel do professor (KENSKI, 2003), além de terem acesso à internet.

\section{CONSIDERAÇÕES FINAIS}

O uso das Tecnologias da Informação e Comunicação no ensino de estudantes da Escola Municipal de Ensino Fundamental Otaviano Paixão Coelho representa um desafio aos professores, pois exige capacitação adequada para permitir a potencialização, a integração, o desenvolvimento e o compromisso social, assegurando a formação de um cidadão participativo e comprometido com sua aprendizagem. O professor mediador do conhecimento necessita integrar-se, provocar a curiosidade e criatividade do aluno em buscar novos caminhos e novas aprendizagens.

Hoje, o uso das tecnologias tornou-se fundamental na educação.Buscar a superação das práticas que se limitam à transferência de informações é de suma importância, superar os anseios e dificuldades é necessário, pois com esse avanço muitos são os desafios, onde o papel da escola e do professor é promover além do conhecimento a autonomia, criatividade, reflexão crítica, espírito colaborativo, empreendedorismo, autonomia e a fluência tecnológica.

Ressalta-se que as tecnologias estão sendo adotadas por muitas escolas, e estas se preocupam em montar laboratório de informática, e trazer novos recursos para acompanhar e teoricamente suprir as necessidades que os avanços provocam. Nesta direção, grandes são as perspectivas de mudanças para preparar e formar indivíduos informados, críticos que abrem novos caminhos. Porém, não basta somente ter a tecnologia na escola, é preciso ensinar o professor usá-las pedagogicamente, por isso a escola também deve preocupar-se em capacitar o professor para trabalhar com as mesmas, para assim explorar recursos compartilhando conhecimentos.

O professor moderno, considerando a especificidade do seu papel enquanto mediador do processo pedagógico, precisa ser capaz de utilizar as tecnologias educacionais inovadoras, auxiliando os estudantes, elaborando materiais didáticos diferenciados, problematizando as atividades de estudo, podendo assim, organizar um diagnóstico para melhoria da ação educativa, mobilizando condutas colaborativas e interativas. Tudo isso melhora as instâncias do ensinar, aprender e investigar desenvolvendo autonomia requerida nesta modalidade de ensino e fortalecendo a inclusão da tecnologia para a sociedade.

\section{REFERÊNCIAS}

ALMEIDA, M.E.B; PRADO, M.E.B.B. Integração tecnológica, linguagem e representação. 2009. Disponível em: http://midiasnaeducacao-joanirse.blogspot.com/2009/02/integracao-tecnologica-linguagem-e.html Acesso: out/2012.

ALMEIDA, M.E.B. Novas Tecnologias e Formação de Professores Reflexivos. Revista Nova Escola. Planejamento e avaliação. 2003. Disponível em: http:// revista escola.abril.com.br./(planejamento-e-avaliação/ entrevista-pesquisadora-puc-sp-tecnologia sala de aula-568012.Shtm./ acesso em out/2012.

DAMASCENO, M. A. MERCADO, L. P.L. ABREU, G. N. Formando professor pesquisador do Ensino Médio. Maceió: edufal.2007.

ENRICONE, D.A A dimensão pedagógica da prática docente futura. In: ENRICONE, D. (orgs). A docência na educação superior- sete olhares. Porto Alegre: Evangraf, 2006. 
HAMZE, A. Linguagem Audiovisual e a Educação. 2010. http://www.educador.brasilescola.com/gestao-educacional/linguagem.htm. Acesso em nov/2012

KENSKI, V. M. Tecnologia e as Alterações no Espaço e Tempo de Ensinar e Aprender. São Paulo: Papirus, 2003.

KENSKI, V. M. Novas tecnologias: o redimensionamento do espaço e do tempo e os impactos no trabalho docente. Revista Brasileira de Educação. n.8, p. 57-71, 2010. Disponível em:

<http://www.anped.org.br/rbe/rbedigital/RBDE08/RBDE08 07 VANI MOREIRA KENSKI.

PDF. Acesso em: out/2012

LÉVY, P. As tecnologias da inteligência. Rio de Janeiro: 341993.

Pierry. Cibercultura. Rio de Janeiro: Ed.34, 1999.

MARTINSI. M.C. (2008). Situando o uso da mídia em contextos educacionais. Disponível em: $\underline{\text { http://midias- }}$ naeducacao-joanirse.blogspot.com/2008/12/situando-o-uso-da-mdia-em-contextos.html Acesso:nov/2012.

MORAN, J. M. Mudar a forma de ensinar e aprender com tecnologia: Transformar as aulas em pesquisa e comunicação presencial- virtual. Especialista em projetos inovadores na educação presencial e a distância. $16^{\circ}$ ed. Campinas: Papirus, 2009, p. 11-65.

MERCADO, L. P. L. Novas tecnologias na educação: Reflexões sobre a prática. Luís Paulo Leopoldo Mercado. Maceió: Edufal. 2002.

PERRENOUD, P. Dez novas competências para ensinar. Artmed, 2000.

PORTO, A. Um olhar comprometido com o ensino. Belo Horizonte: FAPI, 2009.

ROSINI, A. M. (2007). As novas tecnologias da informação e a educação à distância. São Paulo:Cengage Learning.

SAMPAIO, M.N; LEITE, L. S. Alfabetização tecnológica do professor. 5. ed. Petrópolis: Vozes, 1999.

TARJA, S.F. Informática na Educação: Novas Ferramentas Pedagógicas para o Professor da Atualidade. São Paulo. Erica, 2000.

Educação em Rede (http://www.youtube.com/watch?v=AJ1P6aeR6Lo)

ANEXO 1

Questionário

Convidamos você professor para participar desta pesquisa que objetiva auxiliar no processo de ensino-aprendizagem dos alunos da escola. Não existem respostas certas nem erradas. Será útil na medida em que seja sincero (a) em suas respostas. O questionário é anônimo, não se identifique. Obrigada pela participação!

1-Sexo
( ) Feminino
( ) Masculino

2- Qual sua idade?

( ) até 20 anos ( ) de 31 a 35 anos ( ) de 46 a 50 anos 

( ) de 21 a 25 anos
( ) de 36 a 40 anos
( ) de 26 a 30 anos
( ) de 40 a 45 anos
( ) mais de 50 anos

3- Qual é sua formação?

( ) Magistério

( ) Curso Superior. Qual

( ) Especialização(Pós-Graduação Lato Senso). Qual

4- Número de alunos que possui?
( ) até 10 alunos
( ) de 20 a 30 alunos
( ) de 40 a 50 alunos
( ) de 10 a 20 alunos
( ) de 30 a 40 alunos
( ) mais de 50 alunos

5. Assinale qual (is) a(s) mídia(s) que você mais utiliza para se manter informado (a)? ( ) jornal impresso ( ) TV r ( ) rádio ( ) revistas ( ) internet

( ) outros, especifique:

6- Você já realizou algum curso de capacitação para o uso das tecnologias em sala de aula?
( ) $\operatorname{Sim}$
( ) Não

7- Os recursos tecnológicos que a escola possui estão sempre disponíveis para o uso, e o acesso é livre para os professores e alunos?
( ) $\operatorname{Sim}$
( ) Não
( ) as vezes

8- A escola possui algumas tecnologias citadas abaixo. Assinale quais você ocupa frequentemente no auxilio do ensino-aprendizagem com seus alunos:
( ) Aparelho de som
( ) laboratório de Informática
( ) Televisão/DVD
( ) Data show
( ) Computador
( ) máquina fotog. Digital mos?

9- Você tem alguma experiência com computador/internet? Já tem domínio dos mes-

10- Você costuma utilizar o computador/internet para preparar suas aulas?
( ) Sim
( )Não

11- Se sim, cite algumas ferramentas que utiliza no mesmo:
( ) Editor de texto
( ) Planilhas de cálculos
( ) apresentadores de texto
( ) Internet
( ) Jogos

12- Você utiliza o laboratório de Informática da escola com os alunos usando os computadores disponíveis, para auxiliar na aprendizagem dos mesmos?
( ) Sim
( ) Não
( ) as vezes

13- Professor, você costuma estimular os alunos a usarem o computador/ internet dando sugestão de páginas da web para serem usadas por eles na elaboração de trabalhos?
( ) Sim
( ) Não

14- Se você já utilizou o laboratório de informática com seus alunos e incentiva os mesmos a pesquisa, que avaliação faz:
( ) Positiva
( ) Negativa

15-Quais dificuldades você encontra no uso das tecnologias em sala de aulas? 
16- Você concorda que o uso das Tecnologias na Educação pode ajudar no ensino-aprendizagem?
( ) $\mathrm{Sim}$
( ) Não

Porque

17- Quanto ao vídeo que assistiu você concorda que usando as tecnologias nas aulas e mudando nosso método de ensino, poderemos ver uma transformação significativa na aprendizagem dos alunos? ( ) $\operatorname{Sim}$

( ) Não

Justifique sua resposta: 